\title{
The Building of Epistemic Trust: An Adoptive Family's Experience of Mentalization-Based Therapy
}

\author{
Areej Anwar Jaffrani \\ Department of Psychology and Language Sciences, University College \\ London and Anna Freud National Centre for Children and Families, \\ London, $U K$ \\ Theo Sunley \\ Department of Psychology and Language Sciences, University College \\ London and Anna Freud National Centre for Children and Families, \\ London, $U K$ \\ Nick Midgley \\ Child Attachment and Psychological Therapies Research Unit (ChAPTRe), \\ UCL and Anna Freud National Centre for Children and Families, London, \\ $U K$
}

Corresponding author: Areej A. Jaffrani. Email: areej.jaffrani.15@ucl.ac.uk.

Areej A. Jaffrani has a BA from McGill University in Canada and an MSc in Developmental Psychology and Clinical Practice from UCL and Anna Freud National Centre for Children and Families in the UK. She has also undergone an intensive Play Therapy Training from the Canadian Association of Play Therapy and Sandplay Therapy Training from Association of Sandplay Therapy. She currently resides in her hometown of Karachi, Pakistan where she works as a private practitioner and Emotional Well-Being Team Leader at a private school. 
Nick Midgley is a child and adolescent psychotherapist and an associate professor at UCL, where he is the programme director for the MSc in Developmental Psychology and Clinical Practice. Nick is also co-director of the Child Attachment and Psychological Therapies Research Unit (ChAPTRe) at UCL / the Anna Freud National Centre for Children and Families. His books include (with Mick Cooper and Jac Hayes) Essential Research Findings for Child and Adolescent Counsellors and Psychotherapists (Sage, 2017).

Theo Sunley studied Psychology BSc at Bristol University and 'Developmental Psychology and Clinical Practice' MSc at UCL. He is currently a Trainee Clinical Psychologist working in secondary care with adults in Waltham Forest. 


\section{The building of Epistemic Trust: An Adoptive Family's Experience of Mentalization-Based Therapy}

Recently, theorists have posited the development of epistemic trust - the trust in others as reliable sources of information - as an essential aspect of the therapeutic relationship and a mechanism of therapeutic change. Epistemic trust is likely to be disrupted in adoptive children and families and Mentalization Based Treatment (MBT) aims to explicitly promote its development. Therefore, this study aims to investigate how epistemic mistrust is addressed and how epistemic trust is established within the MBT framework. This single-case, exploratory study reports data from in-depth interviews with one adoptive family, which were analyzed qualitatively using Interpretative Phenomenological Analysis. Two superordinate themes are reported: pre-therapy factors contributing to epistemic mistrust and factors contributing to the development of epistemic trust. The findings highlight two critical elements in establishing epistemic trust: the use of certain clinical skills that help build a secure base within therapy and the possibility of trust being transferred from and to other professionals/systems beyond therapy. Hence, this study informs a deeper understanding of how epistemic trust may be built in therapeutic work with adopted children and identifies possible clinical approaches that may be used by clinicians working with this client group.

Keywords: epistemic trust; adopted children; mentalization-based therapy 


\section{Introduction}

Maltreatment and especially relational trauma are the most common reasons why children are removed from the care of their birth parents and placed for adoption (DfE, 2016). Developmental researchers have long been aware of the wide range of effects of early maltreatment, including high rates of mental health problems (Ford, Vostanis, Meltzer, \& Goodman, 2007). Recent studies have also established that early maltreatment and relational trauma is the most common cause of epistemic mistrust or hypervigilance (Fonagy et al., 2015; Knox, 2016) - an exaggerated vigilance towards incoming information. Although there is a paucity of empirical research, it is believed this hypervigilance prevents adopted children from making use of new relationships for social learning. Moreover, given the high levels of scrutiny during a complex adoption process, it is possible that adoptive parents may also become prone to epistemic hypervigilance, especially in relation to the professional network (Malberg, 2015). Therefore, it becomes imperative to investigate how epistemic trust (ET) can be promoted in adoptive children and families to allow them to learn and build relationships, both within and beyond therapy.

Epistemic Trust (ET) has been postulated not only as a key element of early development, but also as a core aspect of the therapeutic relationship and a mechanism of change in psychotherapy (Fonagy and Allison, 2014; Fonagy \& Campbell, 2015). ET has been defined as "an individual's willingness to consider new knowledge from another person as trustworthy, generalizable and relevant to the self" (pg. 4). From a developmental perspective, it is believed to be the way in which human infants learn about their world from trustworthy 
others. Mentalizing - the process of understanding behaviors in terms of mental states such as thoughts and feelings (Bateman \& Fonagy, 2004) - is considered a key component for establishing ET (Fonagy \& Campbell, 2015). When provided, especially in the context of secure attachment, it enables the infant to relax its epistemic vigilance, creating an environment apt for building ET (Fonagy \& Campbell, 2015). A 'virtuous circle' of ET and secure attachment is thereby established.

In the context of therapy, it has been proposed that an increase in clients' mentalizing capacities and mentalization in therapy allows them to move from epistemic hyper-vigilance or mistrust to ET (Kongerslev, Simonsen, and Bo, 2015; Fonagy, Campbell and Bateman, 2017). According to Fonagy et al. (2015), building ET reduces people's rigid ways of thinking and behaving, enabling them to learn from new experiences and changing the way they understand their own and others' mental states. This makes building ET one aim of therapy, as it may enable clients to learn from therapy and generalize benefits to their wider social contexts (Fonagy \& Campbell, 2015).

Mentalization based therapy (MBT; Bateman \& Fonagy, 2004) aims explicitly to promote the building of ET (Muller \& Midgley, 2015). Recently, MBT has been adapted for work with families (MBT-F; Asen \& Midgley, in press), and preliminary work has been done with adoptive children and families (Muller, Gerits, \& Siecker, 2012; Midgley, Alayza, Lawrence \& Bellew, 2017). MBT with families is based on the view that mentalizing is a relational phenomenon and that improved mentalizing capacity can result in improved family relations (Asen and Midgley, in press). 
Although there are now preliminary theories about what contributes to ET in clinical contexts, there has been very little empirical study of how the MBT framework can help to establish ET in the context of work with clients where issues of epistemic mistrust and hypervigilance may be highly salient, such as adoptive families. Furthermore, the way ET is established in a clinical setting has not been explored from clients' perspectives. Hence, this study aimed to explore from the clients' perspective how ET can be established in the context of MBT work with adoptive families.

\section{Methods}

\section{Background and setting}

In 2015, a leading adoption agency in the UK began providing an adaptation of the MBT intervention, Adopting Minds, as part of post-adoption services to families facing relational or mental health difficulties. This was a short-term ( six session) intervention for adoptive families, where the therapist used an adapted version of MBT. A wider evaluation of the project revealed that families receiving the intervention were satisfied and felt supported and contained (Midgley, et al., 2017). As part of that wider study, families completed post-session questionnaires, the Helpful Aspects of Therapy (HAT) forms (Llewelyn, Elliott, Shapiro, Firth, \& Hardy, 1988) to provide feedback on the helpful/unhelpful aspects of therapy after each session, and a small number of families also agreed to be interviewed in-depth about their experiences of therapy (Midgley et al., 2017). This feedback highlighted the theme of trust and mistrust as key elements of therapy. In order to investigate this issue in more depth, this related project was undertaken to explore client's 
perceptions on how epistemic mistrust is addressed in MBT and how a degree of ET may be established with adoptive families.

\section{Research design}

The current study took an exploratory, qualitative approach, focusing on one specific - but potentially core element - of the MBT model i.e. overcoming epistemic mistrust and establishing ET. The study used a case study, idiographic approach (Smith, Harré, \& Van Langenhove, 1995). Semistructured interviews were carried out and analyzed using Interpretative Phenomenological Analysis (IPA; Smith, Flowers, \& Larkin, 2009), which is suitable to an idiographic approach since it offers an in-depth understanding from participants' unique perspective of how they make sense of their experiences.

\section{Procedure}

For the overall evaluation of the project, a small battery of pre/post measures was used with all 36 families receiving the Adopting Minds intervention, and a small number of families took part in in-depth post-therapy interviews (Midgley et al., 2017). As the aims of the current study were to explicitly understand how MBT can help to establish ET with children and families where there may be high levels of initial epistemic mistrust, one case was purposively selected (Teddlie \& Yu, 2007), because issues of trust and mistrust appeared to be central to the family's experience and the therapeutic work. As the clinical work had a positive outcome (based on the quantitative measures and the family's own narrative of their experience), the case was selected in order to explore the process through which epistemic mistrust was addressed and overcome in a therapeutic context with adoptive families. The 
family was therefore invited for a second, follow-up interview, in which the issue of trust in therapy was more explicitly explored. These two interviews formed the data set for this study.

The first interview was based on an adaptation of the Expectations of Therapy Interview (Midgley et al., 2011) to explore families' experiences of therapy in relation to seven broad categories: difficulties that brought the family to therapy; parents' understanding of difficulties; story of therapy; evaluating therapy; change; ending; and other therapies. The second interview explored three broad categories: relationship with therapist; trust/mistrust; and mentalization in sessions. The interviews, which lasted 60 and 90 minutes, were conducted by the first and third authors, who were both research psychologists and had no relationship with the family, the MBT therapist or any other agencies outside of the research. Interviews were audiotaped and transcribed verbatim.

\section{Participants}

The Coswald family (all names are pseudonyms, and identifiable features removed), consists of Dad, a single parent, and two daughters, Catherine aged 16 and Miriam aged 11 (at the time of first interview). The siblings were removed from their birth family when Miriam was born, and Catherine was aged 4 . The children moved foster placements before being adopted at ages 7 (Catherine) and 2 (Miriam) by Dad. At the time of the first interview the children had been adopted for 9 years. Dad and Catherine attended all six sessions; Miriam attended three. After finishing therapy (with an experienced systemic therapist trained in MBT, referred to as Mrs. A), the family received further therapy from a subsequent therapist, referred to as Mrs. B. 


\section{Data analysis}

Data was initially coded and analyzed by the first author of the study. Interviews were analyzed using Smith et al.'s (2009) step-by-step guide for IPA analysis and both transcripts were treated as one 'data set'. The data was first described using initial notes according to three categories: descriptive (focused on describing the content), linguistic (focused on the language's specific use), and conceptual (focused on interpretative level). These comments were then used to develop emerging themes keeping in mind not only a certain part of the data but also the whole interviews. Connections across common themes were identified and similar themes were clustered together, which allowed subsuming themes to develop superordinate themes. This preliminary analysis was then discussed with the third author, an experienced qualitative researcher. This resulted in five candidate themes, which were named and described, resulting in a preliminary report. Finally, discussions with the research team resulted in further analysis of the data at a higher level, resulting in the identification of two super-ordinate themes.

\section{Ethical considerations}

UCL Research Ethics Committee granted ethics approval (Reference ID: 0389/009). Informed consent was obtained from all families to be part of the study and any identifiable information was disguised and all names changed to maintain anonymity. The family was provided a summary of key findings and were given the opportunity to feedback their comments on the results and how their confidentiality was maintained.

Findings 
During both interviews, trust emerged as a key element of the Coswald family's engagement with several agencies/professionals. Thus, the findings relate not only to involvement with the new therapist, Mrs. A, but also with other agencies/professionals such as social services, the post-adoption agency, and Mrs. B (a subsequent therapist). Consequently, this section first describes the context in which the family began therapy at the post-adoption service. Next, two interrelated super-ordinate themes are presented: factors contributing to epistemic mistrust (with three subthemes) and factors contributing to epistemic trust (with two subthemes). Understanding factors contributing to mistrust was deemed important since exploring this would deepen our understanding of the barriers to establishing trust. Lastly, as the family came into therapy largely due to difficulties faced by Catherine, they largely focused on Catherine's experiences. Therefore, some themes/subthemes relate to only Catherine while the remaining ones focus on the whole family. This is indicated within each theme/subtheme separately. Figure 1 illustrates a graphic summary of this section.

\section{Background of family's experiences before beginning MBT}

Prior to beginning therapy, the family reported mistrust in some pre-adoption and post-adoption services, separate from their own adoption agency:

Catherine: I don't have a good relationship with social services altogether because they never trusted me when I said something.

Dad: places like social services...I don't trust them...got no trust or faith in them.

Catherine's early adverse experiences and the family's difficult experiences with previous professionals seemed to have left them cautious of professionals 
generally. Nevertheless, trust was eventually established between the therapist, Mrs. A, and the family:

Catherine: Generally in sessions I did put my wall down, I let out my anger... I actually cried during a couple, which I wouldn't have done in front of many people... and [Mrs. A] made me trust her, so then I let out all...the problems and I shared all of my emotions.

The family felt that the therapy resulted in a range of improvements. Within therapy, Catherine described moving from hiding her emotions to expressing them openly. Outside therapy, positive changes were also narrated, including increased trust between Catherine and her Dad and friends, improved family life, and a willingness to trust a subsequent therapist, Mrs. B. These improvements were attributed by Catherine to MBT:

I did trust [Mrs. A] to...be able to help me because...through all the sessions... of me putting my guard down it helped my relationship with my dad and my sister a lot better...

Hence, Catherine's realization of the therapy's benefits seemed to have resulted in a positive cycle: improvements attributed to therapy seemed to have resulted in trust in therapist, which appeared to have resulted in Catherine's willingness to open up more generally, allowing her to benefit further from Mrs. A, her father and other adults, including Mrs. B.

\section{Theme 1: Factors contributing to epistemic mistrust}

This section began by exploring how the family did feel mistrustful of certain professionals prior to receiving MBT therapy. This theme explores three factors (subthemes) that appeared to have contributed to this from the family's 
perspective: Catherine's adverse early experiences, minimal effort by professionals, and rigidity of frameworks.

Catherine's adverse early experiences.

Catherine's early history of non-safety seemed to have left her mistrustful of adults, as Dad described:

From a very early age...Catherine... was taught not to trust adults... and you [Catherine] had absolutely no trust in adults...you were not allowing people to see the inner you...you put up an incredibly hard shell because you didn't want to be vulnerable...

It seemed that mistrust manifested in Catherine's difficulties with expressing her true thoughts and feelings, which continued beyond Catherine's early years to her time in foster care:

Catherine: there were many problems [in foster care] so I used to tell about these problems ...but [social workers] wouldn't listen to me...it was...really difficult because...this was a place that's supposed to be safe but it wasn't...and that's why I had like really bad [relationship] with social [services]...I've never trusted them since.

Thus, it appeared that Catherine's adverse early years combined with her difficult experiences in foster care had made her cautious of trusting adults including some professionals.

Minimal effort by professionals.

The family's reluctance to trust professionals seemed to have partly been driven by the family's perception of professionals' level of effort as minimal:

Dad: Places like [social work team A]...I just don't trust them...they set us these three bits of so called work that we had to do...we had a big argument 
about that, setting it up time wise... so we went off and we just did it...we came back in good time...And they hadn't even started their side of things...

It appeared that a lack of consistency, reliability and inability to meet timeframes by social care professionals left the family feeling cautious of turning to them for help. However, the current adoption agency's effort level seemed to have surpassed the family's expectations by going beyond their prescribed duties. For instance, the family described the current adoption agency actively advocating for their needs to find an appropriate therapist during crisis time.

Rigidity of frameworks.

The perceived rigidness of professionals' frameworks also appeared to have contributed to mistrust. The family described professionals being inflexible like 'robots'. Dad described his frustration:

You can't actually deal with [social workers] because they work within such narrow sets of rules...it's almost like they can't use their own brains...or their own imaginations to actually come up with a solution...they have to work in...so rigid framework...

Thus, this perceived rigidity resulted in frustration straining the family's relationship to social care services.

\section{Theme 2: Factors contributing to epistemic trust}

In this section, two subthemes explore factors believed to have contributed to the family's growing trust in professionals. These include 'therapy room: $a$ safe space' and 'importance of previous trusted figures/systems.'

Therapy room: a safe space. 
This subtheme encapsulates the notion that for Catherine in particular, trust depended on a feeling of safety, and examines specific elements that contributed to a feeling of safety within the therapy setting. These include the therapist's skills, and time within and across sessions.

The therapist's skills. Mrs. A's skills such as being empathetic, and curious about Catherine's experiences appeared to have contributed to a feeling of safety for Catherine. She described Mrs. A as highly non-judgmental, making it easier for her to express herself:

I felt like I could say anything and she'd just take it on and she wouldn't judge me for it...she wouldn't say anything bad about it...she'd just allow me to talk about it...

Catherine described being able to express any, including negative, thoughts and feelings to Mrs. A. This enabled her to not only understand these herself but also express how she was truly feeling. Moreover, Mrs. A allowing all family members to voice their perspectives and being respectful of them seemed to have encouraged Catherine in sharing her viewpoint:

[Mrs. A] was listening to everything that I was saying, and taking me into consideration...listening to dad, seeing the differences, seeing how the two could help...me understand that I don't have to have my wall up

It appears that Mrs. A's non-selective listening seemed to have supported her in maintaining a non-judgmental attitude. Hence, perceiving the therapy room as safe. Additionally, Mrs. A's ability to and support Catherine under any circumstances seemed to have shown her that she was able to empathize with her. Catherine also described Mrs. A's ability to accurately recognize what she was feeling but could not display, verbally or non-verbally: 
At the start of the sessions...I didn't show my emotions on my face either ...I didn't know how [Mrs. A] knew...but she knew when I was upset, when I was angry when I was...just about to cry... she knew when I was happy and I don't know how she did it at all.

Hence, it appeared that Mrs. A's close attention to the slight differences in Catherine's facial expressions supported her ability to accurately distinguish between Catherine's various emotions. By showing Catherine that she could, in fact, understand and respond congruently to what she was truly feeling even when these were hidden, Mrs. A was able to demonstrate empathy towards her. Furthermore, Catherine described Mrs. A's genuine curiosity in her experiences to be important:

She asked me questions which was pretty good because they were...directed at me so there was no possible way I could have moved on to someone else which is generally what I did. But the questions were directly at me, which made me feel like I could say and that I should be saying something so I ended up...doing that more...

Thus, it appeared that persistently addressing Catherine rather than solely focusing on Dad, and respecting her opinions, Mrs. A was able to show genuine interest in understanding Catherine's experiences and the reasons underlying her behaviors.

Consequently, it seemed that Mrs. A's skills provided Catherine with a positive experience, different to her past experiences. This may have demonstrated to Catherine that there was room within therapy for understanding her mind. 
Trust: a process that requires time to establish. Dad described Catherine as reluctant to engage at the beginning of therapy. However, Catherine described gradually opening up to Mrs. A as therapy progressed and letting her guard down slightly in each session:

Having the amount of sessions that we did...each session I suppose I let my guard down that little bit more...until...my guard was that half way up and I could start letting my emotions out which took a little bit of time because...it takes me a long time to realize if I can trust someone or not.

Time appeared to evidence Mrs. A's consistency and permanency supporting her in earning Catherine's trust. This pattern further emerged for Catherine in the adoptive family; Dad described Catherine being mistrustful of the family until her adoption was confirmed:

The first time I think you showed any true emotion was on the day that we legally adopted you...that was a sudden realization that... something might actually be permanent.

Accordingly, it appeared that this experience of permanency had allowed her to trust the home environment as safe by providing reassurance that it would not disappear. Thus, similarly to the therapy room, time seemed to have allowed Catherine to regard her home environment as safe when the adoption proved to be permanent.

Importance of previous trusted figures/systems.

This theme illustrates the importance previous trusted figures/systems played determining for the whole family their level of confidence in a therapist/professional. This seemed to be mediated by the professionals' 
affiliation with previous trusted figure/systems and gender of the previous trusted figures.

Professionals' affiliation with previous trusted figure/systems. The perceptions about, or trust in, a professional/agency seemed to have significantly impacted the family's level of trust/mistrust in that person/system. The following excerpt illustrates this:

Catherine: I trust [the post-adoption agency]. It's one of the few sort of social workers...that I will actually trust. I've had loads...of bad experiences with social workers, so I think the fact that it's here and the fact that dad trusts them and that I tend to trust people here more...than I would somewhere else and the people that...we're going to do the sessions with after [Mrs. B], they've been picked by [the current post-adoption agency], so that means that I will trust that because it has come from here.

Thus, Catherine's capacity to trust the post-adoption agency seemed to have partly been driven by Dad's positive experiences with them. Dad's trust in the adoption agency seemed to have transferred to Catherine's trust in them, which seemed to have contributed to Catherine's trust in Mrs. A. This pattern likewise emerged with Mrs. B; Catherine described finding it easier to trust her partly because the current adoption agency had referred Catherine to her.

Furthermore, Dad described expecting Mrs. A to be helpful primarily because the trusted adoption agency had recommended her. By contrast, Dad stated that he was initially hesitant to trust Mrs. B upon discovering that she had a past connection with a mistrusted social care team:

I had a bit of a mistrust with [Mrs. B] to start with as well...she...apparently was the head of social services in [local area] at one time... and my 
relationship with [local area's] social services has been appalling frankly and so my shields were massively up.

However, despite this initial caution, Dad spoke of how he came to trust Mrs B as well, initially because of his feelings about the post-adoption agency that had recommended her.

Gender of the previous trusted figures. The importance of previous trusted figures was further demonstrated by Dad's belief that Catherine's willingness to trust Mrs. A was partly influenced by the therapist's gender:

While she didn't certainly see [Mrs. A] as a surrogate mum...she was probably...one of the females that you [Catherine] could actually open up to...that you would start to trust.

This was further demonstrated by the fact that Catherine was described as being able to forge better relationships with female teachers compared with their male counterparts. Hence, it seemed that Catherine's trust in previous female figures (including early care by a valued foster carer) had partly transferred to other female relationships.

\section{Discussion}

This study aimed to explore factors contributing to the overcoming of epistemic mistrust and the creation of ET with an adoptive family receiving a mentalization-based therapy, Adopting Minds. The factors contributing to mistrust from the family's perspective included: the elder daughter's adverse early experiences, minimal effort by professionals, and rigidity of frameworks. The factors contributing to trust included creating the therapy room as a safe space impacted by the therapist's skills and appropriate provision of time, and transfer of trust to other professionals/systems based on affiliations with trusted 
figures. The gender of previous trusted figures/systems also emerged as a meaningful finding.

The findings of the study highlight two important elements of ET: the significance of providing families with a secure base within therapy from which to explore (Bowlby, 1988; Malberg, 2015), and the partial transfer of trust/mistrust from one professional/system to another, which can contribute to some overcoming of epistemic vigilance. Key elements of providing a secure base appear to draw on certain parent-infant processes that may parallel therapist-client processes (Holmes, 2011) such as marked mirroring (Knox, 2016). In parenting, mentalizing the infant through caregiver sensitivity and emotional attunement promotes secure attachment enabling the creation of ET (Fonagy \& Campbell, 2015; Knox, 2016). Similarly, having a secure base in therapy, which may be partially driven by feeling that the therapist has a genuine curiosity in one's mind and experience in the therapeutic relationship (Malberg, 2015) helps clients to relax their epistemic vigilance, enabling them to engage in self-reflexive work (Kongerslev et al., 2015).

In contrast, participants' mistrust seemed to be based on an experience that professionals had not shown a genuine interest in them as active individuals, resulting in difficulties in collaborative working. For instance, factors such as minimal effort and rigid frameworks could be classified as the professionals' perceived inability to hold the clients' mental states in mind (Slade, 2007), resulting in needs not being understood and responded to sensitively. Thus, the felt-experience that professionals did not provide a 'good enough' (Winnicott, 1953) experience, by not adapting themselves to the clients' 
needs, may have resulted in them being experienced as figures who were not safe to learn from.

Factors which partially contributed for this family to the creation of ET with professionals, such as feeling that the therapist had a genuine interest in understanding their experience, can be categorized as characteristics of a mentalizing stance (Bateman, Bales, \& Hutsebaut, 2012). Furthermore, additional factors that contributed to trust such as active curiosity, not-knowing and an inquisitive stance (Bateman et al., 2012), focus on individual experiences, attention to verbal and non-verbal cues, the treatment of an adolescent with respect, and congruent responses to emotions are also mentalizing characteristics and important building blocks of any therapeutic relationship (Everall \& Paulson, 2002).

The findings of this study indicate that Rogers' (1951) qualities of curiosity, empathy, warmth and genuineness, which are also elements of an MBT approach (Midgley et al., 2017), demonstrate to clients an attunement to their mind, and that another understands their subjectivity and marks them as intentional agents with their own mental states. This experience of being mentalized (and feeling understood) allows the clients to relax their epistemic vigilance and start to trust the professional as someone from whom they can learn, by providing a 'good-enough environment', building a strong therapeutic relationship and providing a secure base. Thus, this finding supports the notion that mentalization in secure therapeutic relationships may enhance ET (Bateman \& Fonagy, 2004; Fonagy \& Allison, 2014).

Furthermore, findings indicate that allowing time within and across sessions allows therapists to establish a secure base within therapy. The 
findings suggest that time possibly allows participants to survey the environment for dangers and helps to establish a sense of permanency often lacking for these children prior to adoption (Akin, 2011). The role of time or how a lack of permanency impacts on adopted children engaging in therapy has not been fully explored previously. However, further investigation is required to better understand this link.

The findings of this single case study also highlight the possibility of the partial transfer of epistemic trust from one figure to another. Participants' likelihood to trust professionals that were affiliated with previous trusted figures confirms Fonagy and Allison's (2014) notion that ET can be transferred to some degree i.e. learning from therapy can lead to an openness to learn from others outside of that specific therapeutic context. This is crucial, given that most therapies are relatively short-term, and so are more likely to be effective if they can help build a 'virtuous circle' whereby the client can continue to learn from trusted figures in their life beyond therapy. This finding also supports the view that early significant experiences with help-givers can influence expectancies of people in authority, which may then be projected onto therapists/systems (Silverman, 1974). Bevington, Fuggle, and Fonagy (2015) write that one system/worker's non-mentalizing may be transmitted to other systems and ultimately to clients. These theories are in line with the finding that past experiences set up expectancies of what future professionals would be like, impacting the likelihood of developing trust in them. Whilst empirical studies have not explored this phenomenon, numerous studies within the developmental literature have 
considered how testimonial trust is predicted in children (Stephens et al., 2015). According to these, children are likely to trust individuals based on group membership (Hetherington et al., 2014) or who have previously shown benevolent or malevolent behaviour (Vanderbilt et al., 2011). However, findings indicate that trust can only be partially transferred, and needs to be supported in new social environments.

Consequently, the current study helps to illustrate the way in which adoptive families may be prone to epistemic hypervigilance and epistemic mistrust, hindering them from learning socially (Fonagy et al., 2015; Knox, 2016). This is likely due to the absence in non-safe contexts of conditions necessary for moderating natural epistemic vigilance and triggering ET, such as the experience of being mentalized well (Allen, 2012). Moreover, the participants' move from mistrust to trust within therapy was associated with improvements outside therapy and an inclination to trust personal and professional relationships. This supports the notion that ET may be a mechanism of change in psychotherapy by opening people's willingness to learn from new opportunities, both within and beyond therapy (Fonagy \& Campbell, 2015).

\section{Limitations of the study}

Further investigation is required to establish the wider applicability of the study's findings, as the case-study design means that it is not clear whether the process of establishing epistemic trust may be different for other adoptive families, or for other client groups. The aim here was to develop an understanding of a process as it occurred for one particular family, in order to explore the possible mechanisms of establishing ET, 
but makes no claims about how common this process is, or whether these mechanisms are transferable to other contexts. Lastly, as the study is exploratory, further research is required to establish whether the reported factors really do impact epistemic vigilance, or if some other internal processes are at play.

\section{Clinical implications}

This study has a number of key implications for clinical practice with the adoptive population: (1) Considering the likelihood of epistemic mistrust, therapists (whether working with an MBT model or not) should be mindful and explore potential reasons for this, and could initially focus on slowly creating ET, through the use of some of the features identified in this study. Whilst some of the techniques and skills identified may be generic therapeutic skills (such as empathy and respect), others (such as a focus on the client's intentional states) have been specifically highlighted in the MBT literature. The use of these skills may be especially important in time-limited therapies where a disrupted capacity for ET might hinder learning from any relationship. (2) When training professionals in adoption services, an emphasis on being empathetic, non-judgmental, curious, genuine and collaborative is recommended. Additionally, some techniques highlighted in MBT may be a useful addition to existing frameworks. (3) Providing services through agencies already trusted by adoptive families or ones recommended by their trusted figures/systems may be preferable; and where this is not possible, it will be important for professionals to openly address issues of mistrust with adoptive families.

\section{Conclusion}


Through an in-depth exploration of one family's experiences, the study highlighted the importance of establishing ET in the context of adoption services. In doing so, findings indicated that providing a safe environment is imperative, which may be achieved by therapists adapting themselves to reflect their clients' internal states and adopting a mentalizing stance, in which curiosity about the mental states of self and other are central. Moreover, this study indicated that trust in helping figures may be predicted by early significant experiences with helping relationships and may be partially transferred based on characteristics such as group membership, prior experience (both positive and negative) and expertise. Future research will need to establish the relevance of these findings to other families but could have important implications for the training of professionals working in pre and post-adoption services. 


\section{References}

Akin, B. A. (2011). Predictors of foster care exits to permanency: A competing risks analysis of reunification, guardianship, and adoption. Children and Youth Services Review, 33(6), 999-1011. doi: 10.1016/j.childyouth.2011.01.008

Allen, J. G. (2012). Restoring mentalizing in attachment relationships:

Treating Trauma with plain old therapy. Washington, DC: American Psychiatric Press. Asen, E. \& Midgley, N. (in press). Mentalization-Based Approaches to Working with Families. In Bateman, A. and Fonagy, P. (eds). Handbook of Mentalizing in Clinical Practice. 2nd edition. American Psychological Association.

Bateman, A. W., Bales, D., \& Hutsebaut, J. (2012). A quality manual for MBT. Draft presented at Nordic MBT-network meeting, Oslo.

Bateman, A. W., \& Fonagy, P. (2004). Mentalization-based treatment of BPD. Journal of Personality Disorders, 18, 36-51. doi: $\underline{10.1521 / \text { pedi.18.1.36.32772 }}$

Bevington, D., Fuggle, P., \& Fonagy, P. (2015). Applying attachment theory to effective practice with hard-to-reach youth: the AMBIT approach. Attachment \& human development, 17(2), 157-174. doi: $10.1080 / 14616734.2015 .1006385$

Bowlby, J. (1988). A secure base: Parent-child attachment and healthy human development. New York: Basic Books.

Department for Education. (2016). Children looked after in England including adoption: 2015 to 2016. Retrieved from 
https://www.gov.uk/government/statistics/children-looked-after-in-englandincluding-adoption-2015-to-2016

Everall, R. D., \& Paulson, B. L. (2002). The therapeutic alliance: Adolescent perspectives. Counselling and Psychotherapy Research, 2(2), 78-87. doi: $\underline{10.1080 / 14733140212331384857}$

Fonagy, P., \& Allison, E. (2014). The role of mentalizing and epistemic trust in the therapeutic relationship. Psychotherapy, 51(3), 372-380. doi: $10.1037 / \mathrm{a} 0036505$

Fonagy, P., \& Campbell, C. (2015). Bad blood revisited: Attachment and psychoanalysis, 2015. British Journal of Psychotherapy, 31(2), 229-250. doi: $10.1111 /$ bjp. 12150

Fonagy, P., Campbell, C., \& Bateman, A. (2017). Mentalizing, attachment, and epistemic trust in group therapy. International journal of group psychotherapy, 67(2), 176-201. doi: 10.1080/00207284.2016.1263156 Fonagy, P., Luyten, P., \& Allison, E. (2015). Epistemic petrification and the restoration of epistemic trust: A new conceptualization of borderline personality disorder and its psychosocial treatment. Journal of personality disorders, 29(5), 575-609. doi: 10.1521/pedi.2015.29.5.575

Ford, T., Vostanis, P., Meltzer, P., \& Goodman, R. (2007). Psychiatric disorder among British children looked after by local authorities: Comparison with children living in private households. British Journal of Psychiatry, 190, 319-325. Doi: 10.1192/bjp.bp.106.025023

Hetherington, C., Hendrickson, C., \& Koenig, M. (2014). Reducing an ingroup bias in preschool children: The impact of moral behavior. Developmental Science, 17, 1042-1049. doi: 10.1111/desc.12192 
Holmes, J. (2011). Attachment in the consulting room: towards a theory of therapeutic change. European Journal of Psychotherapy \& Counselling, 13(2), 97-114. doi: 10.1080/13642537.2011.570013

Knox, J. (2016). Epistemic Mistrust: A Crucial Aspect of Mentalization in People with a History of Abuse? British Journal of Psychotherapy, 32(2), 226-236. doi: 10.1111/bjp.12212

Kongerslev, M., Simonsen, S., \& Bo, S. (2015). The Quest for Tailored Treatments: A Meta- Discussion of Six Social Cognitive Therapies. Journal of clinical psychology, 71(2), 188-198. doi: 10.1002/jclp

Llewelyn, S. P., Elliott, R., Shapiro, D.A., Firth, J., \& Hardy, G. (1988). Client perceptions of significant events in prescriptive and exploratory periods of individual therapy. British Journal of Clinical Psychology, 27, 105-114.

Malberg, N. T. (2015). Activating Mentalization in Parents: An Integrative Framework. Journal of Infant, Child, and Adolescent Psychotherapy, 14(3), 232-245. doi: 10.1080/15289168.2015

Midgley, N., Alayza, A., Lawrence, H., Bellew, R. (2017). Adopting Minds - a mentalisation-based therapy for families in a post-adoption support service: preliminary evaluation and service user experience. Adoption \& Fostering, O(0), 1-16. doi: 10.1177/0308575917747816

Midgley N., Ansaldo F., Parkinson, S., Holmes, J., Stapley, E., Target, M. (2011). Expectations of therapy interview (Young person and parent versions). Unpublished manuscript Anna Freud Centre, London. Muller, N., Gerits, L., \& Siecker, I. (2012). Mentalization-based therapies 
with adopted children and their families. Minding the Child. Mentalization-Based Interventions with Children, Young People and their Families. Hove: Routledge.

Muller, N., \& Midgley, N. (2015). Approaches to assessment in timelimited Mentalization-Based Therapy for Children (MBT-C). Frontiers in psychology, 6. doi: 10.3389/fpsyg.2015.01063

Rogers, C. R. (1951). Client-centered therapy: Its current practice, implications, and theory. Boston, MA: Houghton Mifflin.

Silverman, L. H. (1974). Some psychoanalytic considerations of nonpsychoanalytic therapies: On the possibility of integration treatment approaches and related issues. Psychotherapy: Theory, Research \& Practice, 11(4), 298-305. doi: 10.1037/h0086368

Slade, A. (2007). Parental reflective functioning: An introduction. Attachment \& human development, 7(3), 269-281. doi: $\underline{10.1080 / 14616730500245906}$

Smith, J. A., Flowers, P., \& Larkin, M. (2009) Interpretative

Phenomenological Analysis: Theory, Method and Research. London: Sage Publications.

Smith, J. A., Harré, R, \& Van Langenhove, L. (1995). Idiography. In J. A.

Smith, R. Harre’ \& L. Van Langenhove (Eds.), Rethinking psychology (pp. 59-69). London: Sage.

Stephens, E., Suarez, S., \& Koenig, M. (2015). Chapter Five-Early Testimonial Learning: Monitoring Speech Acts and Speakers. Advances in 
child development and behavior, 48, 151-183. doi: $\underline{10.1016 / b s . a c d b .2014 .11 .004}$

Teddlie, C., \& Yu, F. (2007). Mixed methods sampling a typology with examples. Journal of mixed methods research, 1(1), 77-100. doi: $10.1177 / 2345678906292430$

Vanderbilt, K. E., Liu, D., \& Heyman, G. D. (2011). The development of distrust. Child development, 82(5), 1372-1380. doi: 10.1111/j.1467$\underline{8624.2011 .01629 . x}$

Winnicott, D. (1953). Transitional objects and transitional phenomena, International Journal of Psychoanalysis, 34, 89-97. 


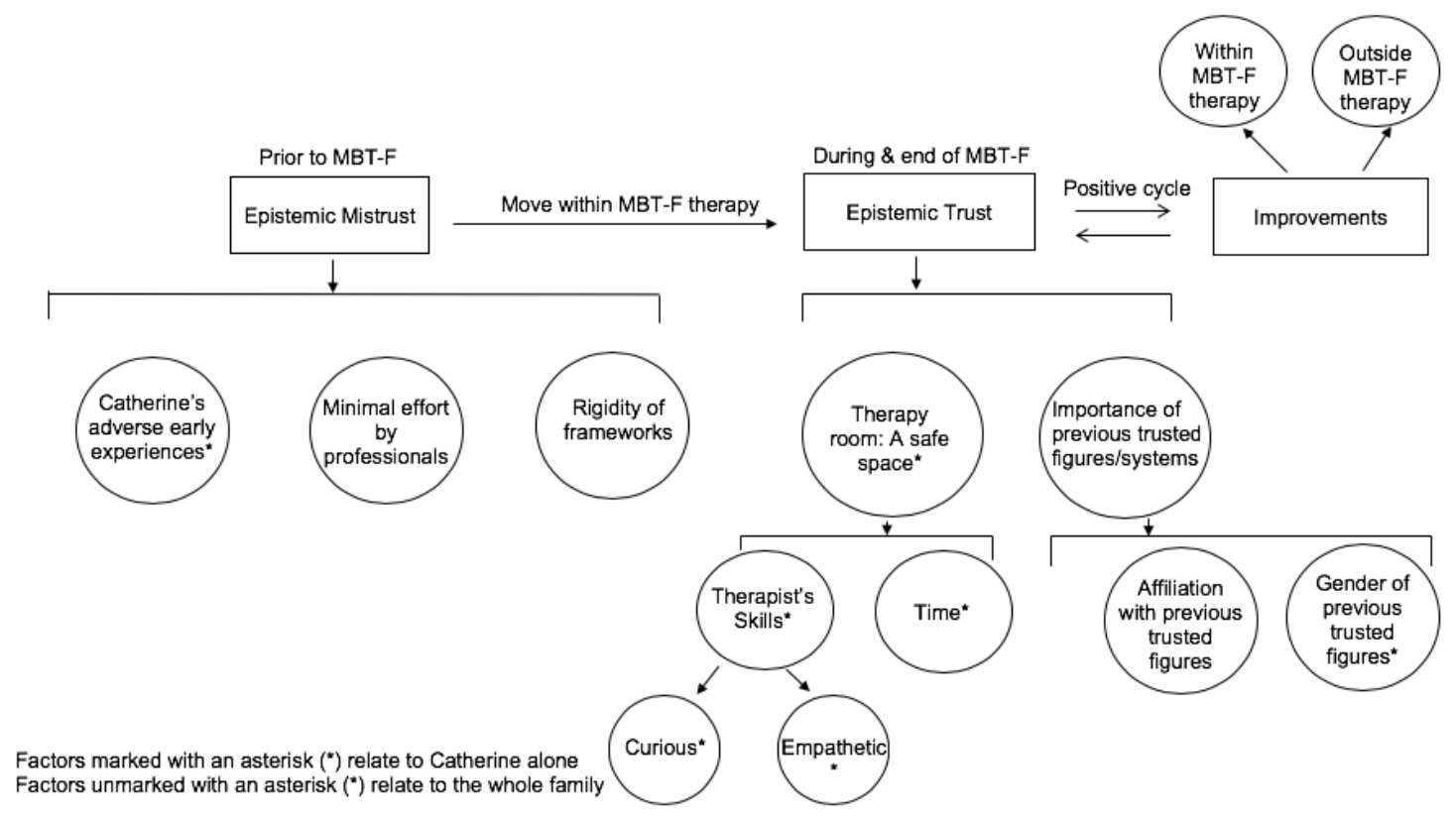

Figure 1. Summary of Findings 
Figure 1. Summary of Findings 